JOURNAL DE PHYSIQUE IV

Colloque C6, supplément au Journal de Physique III, Vol. 1, décembre 1991

C6-137

\title{
AN INVESTIGATION OF CHARGE STATES IN ELECTRON IRRADIATED LOW NITRIDED SILICONDIOXIDE FILMS
}

\author{
V. RANK, M. KOPP, G. WEIDNER* and M. NOVAKOWSKI \\ Department of Physics of Rostock University, Universitätsplatz 3, D-2500 Rostock 1, Ger- \\ many \\ *Institut of Semiconductor Physics, PSF 409, D-1200 Frankfurt/O., Germany
}

\begin{abstract}
MOS-structures with pure SiOn-films, with nitrided $\mathrm{Si}_{-\mathrm{SiO}_{2}}$ interface region and with an insulator layer with uniform weak nitridation. were irradiated with $2 \mathrm{MeV}$ electron beam in steps between $10 \mathrm{krad}\left(\mathrm{SiO}_{2}\right)$ and 2 Mrad $\left(\mathrm{SiO}_{2}\right)$ with and without an electrical field. The electrical characterisation with CV-(CapacitanceVoltage) and DLTS- (Deep Level Transient Spectroscopy) method gives us information about the charge states in this structure. The electron irradiation generates electron-hole pairs and a positive gate field effects a hole drift to the interface, where we can find a positive oxide charge and a rising interface density. The amount of density is a function of nitridation and of the electron beam dose.

The best electrical stability under irradiation induced hole injection is to be found in an uniform nitrided $\mathrm{SiO}_{2}$ layer.
\end{abstract}

\section{Introduction}

Nitrided silicon dioxide layers are further investigated for alternative gate insulator and ultrathin dielectric films. The nitrogen incorporation behaves like a good diffusion barrier / / / for technological impurities and good radiation-hardness performance /3/. Dependent on the nitridation process $s_{i} 0_{2}-f i l m s$ the nitrogen distribution into the layer varies and drifts the electrical properties $/ 1 / . / 2 /$.

The well known characteristics of electrical properties of nitriced films in comparison with silicondioxide are the higher amount of positive oxide charge (equivalent to the negative flatband voltage shift) and the dependence of interface state density on nitridation time and temperature $/ 2 / . / 4 / . / 5 /$.

very important for application is the stability of electrical 
parameter after charge injection. In this paper we investigate the behaviour of trapping processes before and after electron irradiation under a gate field and with different nitrogen distributions in Mos-samples.

\section{Experimental}

The samples were produced with the help of rapid thermal oxidation and nitridation /8/. Starting from <100>n-Si. $10-20$ ohm $\mathrm{cm}$ substrates, a rapid thermal oxidation at $1150^{\circ} \mathrm{C}$ resulted an initial oxide. It was followed by a postoxidation annealing at $1050^{\circ} \mathrm{C}$ in pure nitrogen for $30 \mathrm{~s}$.

Rapid thermal nitridation in ammonia at twoldifferent temparatures $T_{n}\left(1150^{\circ} \mathrm{C}\right.$ for sample 19 and $1000^{\circ} \mathrm{C}$ for sample 22) and a reoxidation process at different $T_{\text {nox }}\left(950^{\circ} \mathrm{C}\right.$ for sample 19 and $1200^{\circ} \mathrm{C}$ for sample 22) should also effect a different nitrogen distribution in the silicondioxid.Afterwards Polysilicon/Al-Dots were applied on samples and the backside got an Al-metallisation. too.

The Auger Electron Spectroscopy (AES) depth proilies of nitrided samples $19 /$. Shown in figure 1 , documents the different nitrogen distribution cause to different sample preparation.

$\%$

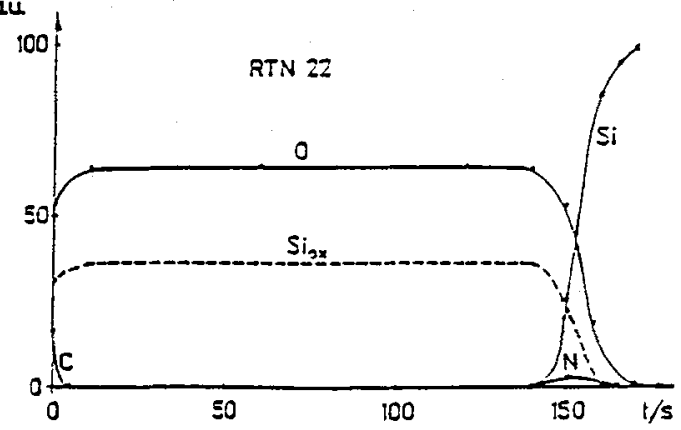

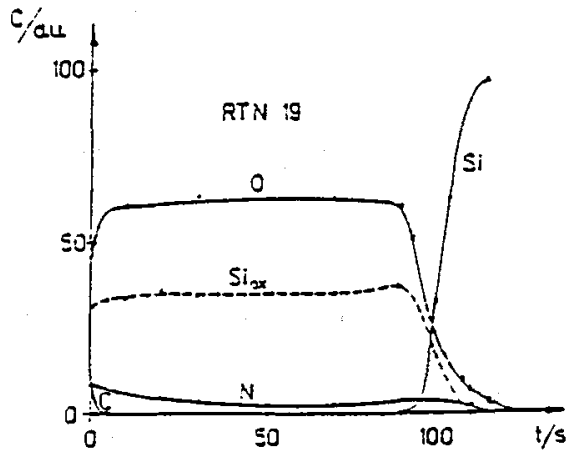

Fig: 1 AES depth profiles

The electron beam source, reported in $/ 6 /$, supplies electron energy to $2 \mathrm{MeV}$. In this energy range the electrons are only slightly in interaction with $\mathrm{SiO}_{2}-\mathrm{Si-structure,} \mathrm{but} \mathrm{they} \mathrm{generate}$ electron-hole-pairs in the insulator with a rate of $8.10^{12}$ pairs per $\mathrm{rad}\left(\mathrm{SiO}_{2}\right)$ and per $\mathrm{cm}^{2} / 6 /\left(1 \mathrm{rad}=6.242 * 10^{-7} \mathrm{MeV} * \mathrm{~g}^{-1}\right.$ for $\left.\mathrm{SiO}_{2}\right)$. The beam dose $D$, defined as beam energy per irradiated mass, was varied from $10 \mathrm{krad}$ to $1 \mathrm{Mrad}\left(\mathrm{SiO}_{2}\right)$.

The positive gate field was $2.5 \mathrm{MV} / \mathrm{cm}$ less than the field necessary for Fowler-Nordheim-tunneling in $\mathrm{SiO}_{2}$. After irradia- 
tion we continued the field for several days.

For electrical characterisation we used the static HF-CV method and lock-in DLTS as shown in $/ 10 /$ and $/ 12 /$.

\section{Results}
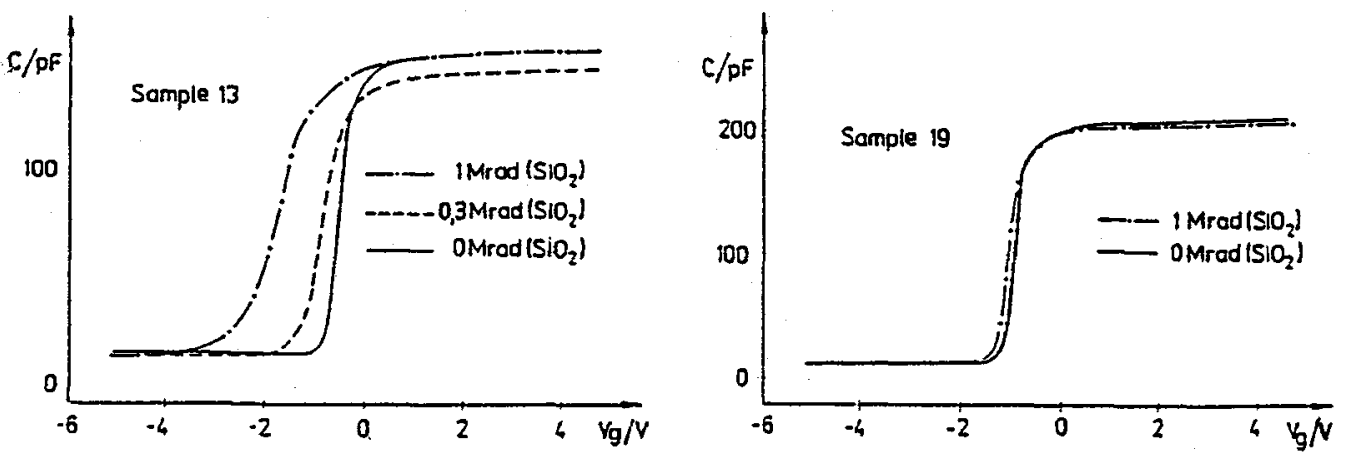

Fig.2 a) CV-characteristics before and after irradiation

After irradation of the samples under positive gate field the capacitance-voltage measurements show changes in interface state density and oxide charge (fig.2).

In many cases ithis statement is also true for the device resistivity. As shown by Awadelkami/13/a great change of the device resistivity first of all is a consequence of the electron beam damage in silicon and the trapping of the electrons there.

\subsection{Oxide charge}

In fig. $3 a$ is shown the change of oxide charge as a function $\rho^{f}$ beam dose $D$ with and without an electrical gate field. The Si02-layer (sample 13, shows the expected behaviour. There is a small change to be noticed without the field. The change increases with the higher number of holes near the interface under the field: Though the value of the oxide charge is higher. the nitridation of the interface (sample 22) doesn't influence this behaviour.

The uniform weak nitrided $\mathrm{SiO}_{2}$-layer irradiated without the field is dependent on irradiation in the same way. However, the dependence of the oxide charge on beam dose decreases when radiated under a positive gate field.

3.2 Interface state density

The change of interface state density Nit pre- and postirra- 
diation is proportional to the difference between change of flatband voltage $\Delta V_{f b}$ and change of midgap voltage $\Delta V_{\text {rigg }}$ In figure $3 b$ and $c$ this difference is presented as a function of the electron beam dose. The irradiation of the pure sioz-layer demonstrated the expected increase in $N_{i t}$. The difference was higher under irradiation with field than without. However, the nitrided samples didn't show any dependence of the interface state density on irradiation without field, which means a higher radiation hardness.

By way of switching on the external field the behaviour of the sample with nitrided interface (sample 22) only became identical with the behaviour of pure $\mathrm{SiO}_{2}-f i l m$. This fact is a good argument for the model conception of the hole interaction that plays a central role in generation of interface states. The interface state density of sample 19 didn't change while increasing beam dose under a field.

The termspectra, found with the help of DLTS-measurements. are documented in.figure 4 ( $N_{i t}=f(E)_{D}$ vith positive field): The virgin oxide (sample 13*) had. $N_{i t}<2 * 10^{9} \mathrm{ev}^{-1} \mathrm{~cm}^{-2}$. Nit increases greater near midgap with rising beam dose. The interface
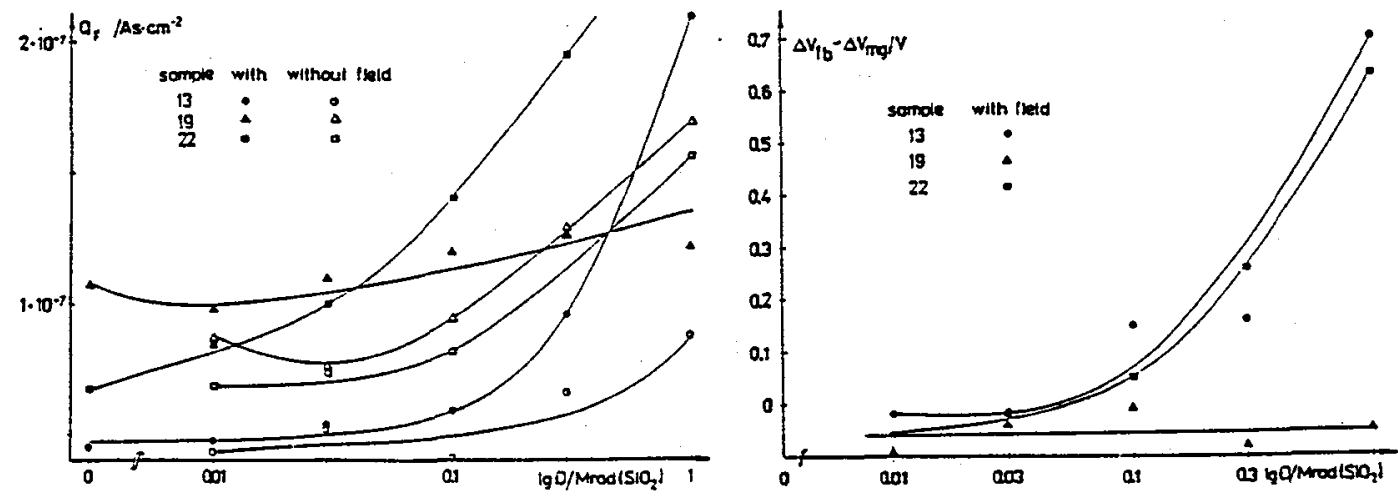

Fig.3 a) oxide charge of all samples as function of beam dose $D$

b) interface state density as function of beam dose

state density of nitrided samples is higher than density of $\mathrm{SiO}_{2}$ before irradiation. but doesn't increase greatly after irradiation.

At the energy level of $\left(E_{C}-0.4\right)$ eV the interface state density. was presented as a function of the injected charge $Q_{i n j}$ in fig. 5. For calculation purposes the injected charge was supposed at a gain of $90 \%$. For the pure silicondioxid layer there was found a Nit-generation rate one hundred times higher than the rate calculated for uniform nitrided films. lie can deduct that 
nitridation changes the generation mechanism for interface states fundamentally. The following model considerates this fact and the forementioned observations.

\section{Conclusion}

As shown by M.Schmidt /7/ the hole generation under positive gate field effects in $\mathrm{Si}_{\mathrm{S}} \mathrm{SiO}_{2}$-structures the breaking of Si-Sibonding (O-vacancy). Si-H- bonding. Si-O-H-bonding and of Si-Otight bonding near interface. The breaking of those bondings generates $E^{\prime}-c e n t r e s$ that work as an increased positive oxide charge: $\mathrm{O}_{3} \equiv \mathrm{Si}^{+} \cdot \mathrm{Si}_{\mathrm{i}} \equiv \mathrm{O}_{3}$

The released single positive charged $\left(H^{+}\right)$, atomic $(H)$ or molecular $\left(\mathrm{H}_{2}\right)$ hydrogen diffuses to the interface and causes, as shown by Grunthaner /14/, the creation of silicon dangling bonds of the form: - $S i \equiv S_{3} \quad\left(P_{b}\right.$-centres) and $\quad S_{i} \equiv S_{2} O$

The nitridation of silicondioxide presumably causes on the one hand a substitution of oxigen by nitrogen or by nitrogen-hydrogen configurations and on the other hand also the reduction of the $\mathrm{Si}-\mathrm{H}$-bondings.In this case the originating $\mathrm{Si}-\mathrm{NH}_{2}-\mathrm{Si}_{2}=\mathrm{NH}-$ or $\mathrm{Si}_{3} \equiv N$-bondings are energetically more stable, as with saturation with hydrogen. Therefore it can be expected that after irradiation and hole generation in nitrided $\mathrm{SiO}_{2}$ a lower oxide charge can be found./16/
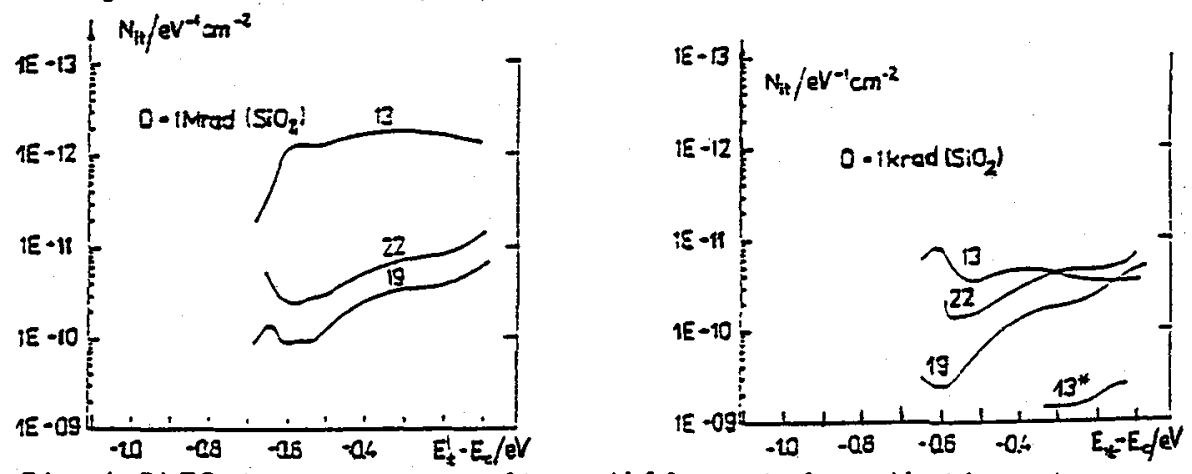

Fig.4 DLTS-termspectra after different irradiation doses

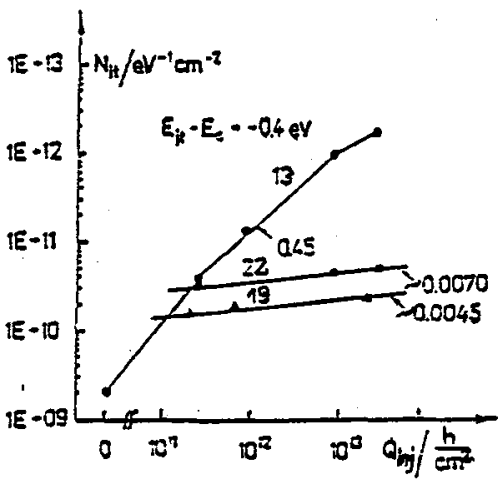

Fig.5 interface state as function of injected charge 
The interface state density vill be less influenced by the Iower portion of free hydrogen. At the same time the integration of nitrogen to interface effects as described by severi /4/, a relaxation of the Si-O-Si-bonds.

This counteracts the breaking of the bonds by hydrogen / $14 /$. The results shown above are in accord with the discribed model:

- The sample with nitrided interface only shows in comparison with pure $\mathrm{SiO}_{2}$, a higher generation of oxide charges. This is certainly due to a higher portion of hydrogen and the conditions of nitridation and reoxidation. The interface state density has clearly improved in this sample after charge injection in comparison with $\mathrm{SiO}_{2}$.

- The equalized nitridation (sample 19) points to a more stablized behaviour of the oxide charge against hole injection, which obviously causes a more decreased generation of interface states. This result corresponds with that described in $/ 3 /$.

The authors would like to thank D.Braunig and the Hahn-MeitnerInstitute (Westberlin) for samples irradiation and support.

\section{References}

/1/G.A. Ruggles et al. J. Electrochem. Soc.Vol.1334(1986)787

/2/F.H.P.M. Habraken et al.J. Appl. Phys. 5310(1982) 6996

/3/R. Sundar'esan et al. IEEE Trans.NS 33 (1986) 1223

/4/ M. Severi et al. Appl. Phys. Lett. 51 (1987) 1702

/5/ B. Balland et al. Phys. stat. sol. (a) $100(1987) 187$

/6/D. Brăunig "Wirkung hochenergetischer Strahlung auf Halbleiterbauelemente" springer Verlag 1989

17/ M. Schmidt Dissertation Berlin 1990

/8/ G. Weidner et al. Proceedings of Conference "Physik der Halbleiteroberfläche" Binz. Germany 1990

/9/ G: Prosch et al. to be published

/10/ E.H.Nicollian!, J.R.Brews "MOS Physicsand Technology" Jonn Wiley \& Sons New York 1982

/11/ N.M. Johnson J. Vac: Sci. Technol. 21 (1982)303

$112 / \mathrm{V}$. Rank. M: Kopp. H. Koster jr. Proceedings of Conf. "Physik der Halbleiteroberfluche" Binz, Germany 1988

/13/0.0. Awadelkarim et al. J. Appl. Phys. 65(12) (1989) 4779

/14/ F: Grunthaner. P. Grunthaner Mat. Sci. Reports 1(1986)65

115 G.Soncini et al. 17th Yugosl. Conf.on Microel.Proceedings Yugoslavian 9:-11. May 1989 Elsevier Oxford

/16/F.H.P.M.Habraken. A.E.T. Kuiper Thin Solid Films 12(1990)193 